\title{
On the Contribution of Volunteered Geographic Information to Land Monitoring Efforts
}

\author{
Jamal Jokar Arsanjani ${ }^{\star}$ and Cidália C. Fonte ${ }^{\dagger}$ \\ ${ }^{*}$ Department of Planning and Development, Aalborg University, A.C. Meyers \\ Vænge 15, DK-2450 Copenhagen, Denmark, jja@plan.aau.dk, \\ jamaljokar@gmail.com \\ ${ }^{\dagger}$ Department of Mathematics, University of Coimbra / INESC Coimbra, \\ Coimbra, Portugal
}

\begin{abstract}
Land-related inventories are important sources of geoinformation for environmentalists, researchers, policy-makers, practitioners, and ecologists. Traditionally, a considerable amount of energy, time, and money have been dedicated to map global/regional/local land use datasets. While remote sensing images and techniques along with field surveying have been the main sources of data for determining land use features, field measurements of ground truth have always amplified the required time and money, as well as information credibility. Nowadays, volunteered geographic information (VGI) has shown its great contributions to different scientific disciplines. This was made possible thanks to Web 2.0 technologies and GPS-enabled devices, which have advanced citizens knowledge-based projects and made them user-friendly for volunteered citizens to collect and share their knowledge about geographical objects. OpenStreetMap as one of those leading VGI projects has shown its great potential for collecting and providing land use information. The collaboratively collected
\end{abstract}

\section{How to cite this book chapter:}

Arsanjani, J J and Fonte, C C. 2016. On the Contribution of Volunteered Geographic Information to Land Monitoring Efforts. In: Capineri, C, Haklay, M, Huang, H, Antoniou, V, Kettunen, J, Ostermann, F and Purves, R. (eds.) European Handbook of Crowdsourced Geographic Information, Pp. 269-284. London: Ubiquity Press. DOI: http://dx.doi.org/10.5334/bax.t. License: CC-BY 4.0. 
land use features from diverse citizens could greatly back up the challenging element of land use mapping, which is in-field data gathering. Hence, in this literature we will look at the completeness, thematic accuracy and fitness for use of OpenStreetMap features for land mapping purposes over European countries. The empirical findings reveal that the degree of completeness varies widely ranging from $2 \%$ to $96 \%$ and overall and per-class thematic accuracies goes up to $80 \%$ and $96 \%$, respectively compared to the European GMESUA datasets. Furthermore, more than $50 \%$ of land use features of eight European countries are mapped. This messages that the harnessing citizens' knowledge can play a great role in land mapping as an alternative and complementary data source.

\section{Keywords}

Land use mapping; Comparative assessment; Global Monitoring for Environment and Security Urban Atlas (GMESUA); OpenStreetMap

\section{Introduction}

Land cover (LC) and land use (LU) inventories contain geoinformation on the coverage and usage of our surrounding lands, respectively. LU and LC inventories are of high importance for many applications with regards to urban and regional planning, policy making, among others. These two concepts present two distinctive concepts, because LU maps explain human activities happening on the land, such as artificial surface construction, farming, and forestry that represent the usage of land (Ellis 2007; Wästfelt \& Arnberg 2013), while LC maps present the physical cover on the ground (De Sherbinin 2002). Traditionally, applying image processing algorithms on remotely sensed data elaborated with ground-truth measurements and other complementary archive data have been the main source of collecting LU and LC features (Qi, Yeh, Li \& Lin 2012; Saadat et al. 2011). Although remote sensing images and techniques often facilitate earth observation efforts, in-field surveying as well as personal interviews with local residents are required for the sake of results' validation, i.e. as groundtruth data coming from in-situ measurements play a critical role in delivering end products (Cihlar \& Jansen 2001; De Leeuw et al. 2011). Therefore, we have to collect ancillary data as well in order to assign appropriate LU types to land parcels. As a result, LU mapping becomes even more complicated than LC mapping, and extensive data collection from local citizens, land managers, and evidence sources are vital for accurate LU mapping (Fritz et al., 2012).

From financial and temporal perspectives, a great deal of budget and time have been dedicated for producing LU and LC maps at global, regional, and 
local scales. Examples of global and regional scale with coarse resolution products include Global Land Cover (GLC)-2000 (Fritz et al., 2003), Moderateresolution Imaging Spectroradiometer (MODIS (McIver \& Friedl, 2002)), and GlobCover (Arino et al., 2012), CORINE 2000 (Büttner, Feranec, \& Gabriel, 2002) and Global Monitoring for Environment and Security Urban Atlas (GMESUA (Seifert, 2009)) among others. In the case of GMESUA, highresolution images including SPOT, RapidEye, and ALOS Images have been utilized to generate fine-scale maps of large metropolitan areas delivering GMESUA (Kong, Yin, Nakagoshi, \& James, 2012). But, the accuracy of them has been the main concern as outlined by (Fritz et al., 2012; Herold, Mayaux, Woodcock, Baccini, \& Schmullius, 2008). Thus, the necessity of having an alternative and complementary solution for mapping LU and LC features is evident. We believe that VGI could be of great importance, because the development of web technologies and large availability of GPS-enabled devices have resulted in the emergence of a large number of VGI platforms, which provide information about geographical objects from citizens (Fonte, Bastin, See, Foody, \& Lupia, 2015). The majority of the VGI-like platforms offer very highresolution satellite and aerial images (from $20 \mathrm{~cm}$ spatial resolution) through image libraries (e.g. Bing Maps) in their interfaces, which enable volunteers to visualize the whole globe with high detail so that they can map a large variety of features and attach respective attributes to them (Rouse, Bergeron, \& Harris, 2007). In other words, a sort of visual analysis and interpretation of satellite images is applied. This convenient and straightforward way of visual interpretation of remote sensing images can be considered as an alternative solution for LU mapping and even achieving finer resolution LU maps than our current stored datasets at a global scale (Jokar Arsanjani, Mooney, Helbich, \& Zipf, 2015). Undoubtedly, OSM has been a pioneer example of VGI and has shown its huge potential for being the Wikipedia of maps exactly as its motto. OSM is a unique platform for several reasons namely, it has attracted a huge amount of public attention and contributions (Ramm et al., 2011) by having exceeding 2.3 million users until today and continues to grow as outlined by Jokar Arsanjani, Helbich, et al. (2015). More importantly, OSM is highly democratic in receiving contributions through enabling any volunteer to add/edit/modify the existing features and sharing the whole data history freely and openly with the public in a structured way (Flanagin \& Metzger, 2008; Koukoletsos, Haklay, \& Ellul, 2012). Moreover, OSM collects geographic information in the form of GIS vector data such as points, polylines, and polygons and releases them based on different tags, which makes it quite user-friendly for end users (Jokar Arsanjani, Helbich, Bakillah, Hagenauer, \& Zipf, 2013; Jokar Arsanjani, Mooney, Helbich, et al., 2015).

An extensive amount of analysis of road networks in OSM has been carried out (Ludwig, Voss, \& Krause-Traudes, 2011; Mooney \& Corcoran, 2012) and a few attempts in analyzing OSM for LU mapping has been conducted. We will 
assess the role of OSM in LU and LC mapping. Besides preparing a LU dataset from OSM contributions, we aim at a) measuring the completeness of OSM LU features, b) cross-comparing the thematic accuracy of the OSM LU features with the GMESUA data through a statistical assessment, c) assessing the fitness for use of OSM for LU and LC mapping.

\section{Materials}

\section{OSM dataset}

A snapshot of OSM features tagged as 'natural' and 'landuse' from November 2013 and February 2014 was collected. The features tagged with 'natural' describe a wide variety of physical features, which are categorized into different categories such as water bodies, forest, etc. as described in (Ramm, 2014). The term 'landuse' concerns the human use of land, which represents the purpose a land parcel is being used for.

\section{Reference dataset}

In this study, the pan-European GMESUA dataset serves as reference data, which comprises LU data for selected metropolitan areas exceeding 100,000 inhabitants. It is prepared for European needs and the contained information has been derived mainly from Earth Observation (EO) data supported by other reference data including commercial-off-the-shelf (COTS) navigation data and topographic maps. It has a minimum mapping unit (MMU) of 0.25-1 ha, and a minimum width of linear elements of $100 \mathrm{~m}$ with $\pm 5 \mathrm{~m}$ positional accuracy (European Union, 2011). It currently covers 305 urban regions within Europe. The minimum thematic accuracy for all classes is $80 \%$. For more details see the Urban Atlas mapping guide (European Union, 2011). Table 1 represents the defined classes and their codes in GMESUA at different levels of details.

\section{Study areas}

In this study, the whole European continent was chosen as the study area for the regional scale analysis and ten random metropolitan areas were selected as case studies for the local scale analysis. These cities including their metropolitan areas are Berlin, Frankfurt am Main, Munich, and Hamburg, Bucharest, Rome, Stockholm, London, Budapest, and Vienna. Having multiple case studies from different countries would help to understand the heterogeneity of contributions in terms of quantity and quality. 


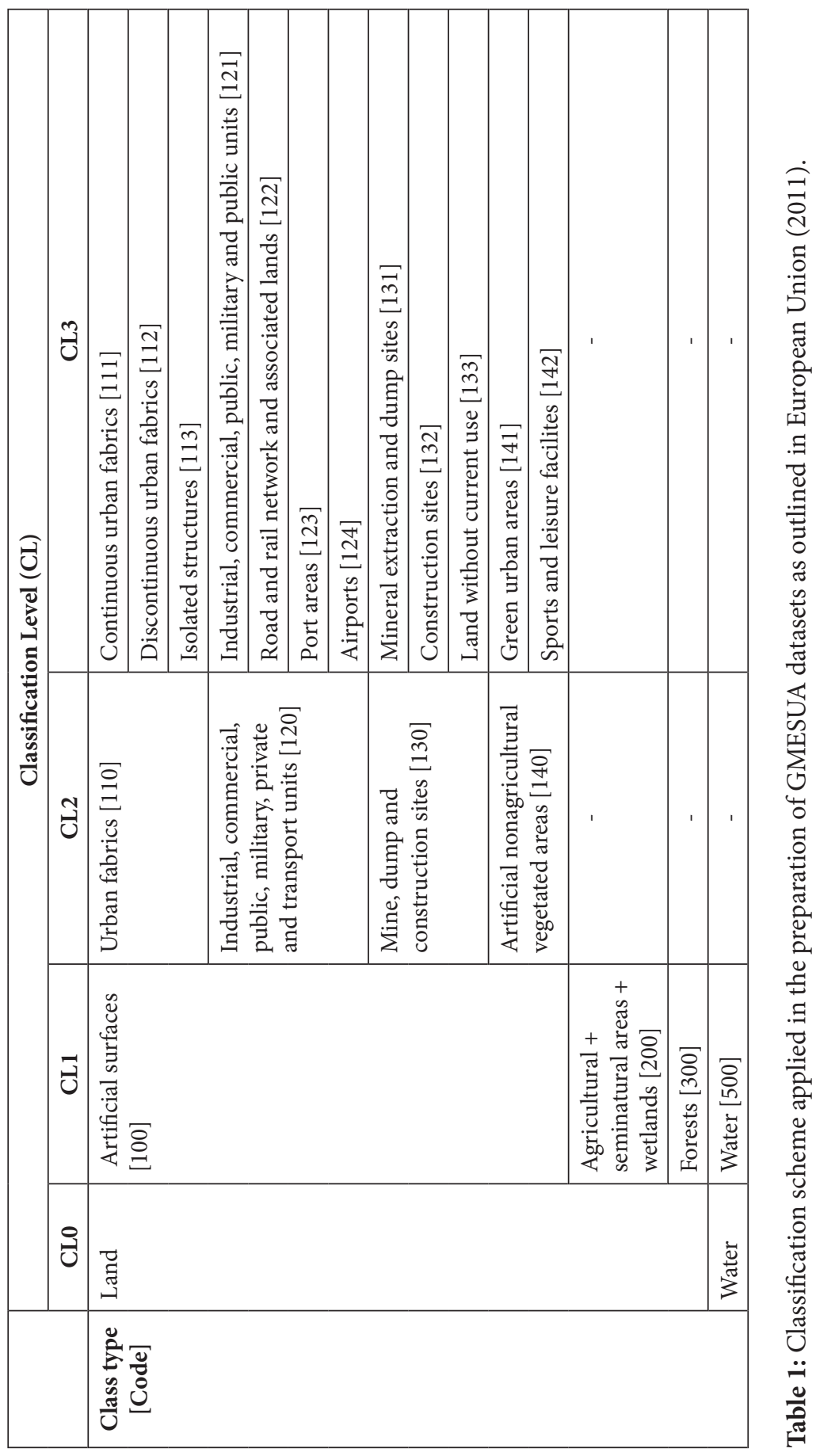




\section{Methods}

Quality of geodata should be considered internally and externally (Gervais, Bédard, Levesque, Bernier, \& Devillers, 2009; Jokar Arsanjani, Barron, Bakillah, Helbich, \& Arsanjani, 2013; van Oort, 2006). Internal quality reflects the specifications in the process of data production that address errors in the data. External quality measures the suitability of a dataset for a particular purpose and addresses its 'Fitness of Use' (FoU: (Devillers, Bédard, Jeansoulin, \& Moulin, 2007; Guptill \& Morrison, 1995)). The major standard organizations (e.g. ISO, ICA, FGDC, and CEN) have described their main criteria for data quality analysis and the following five criteria are common amongst them: (1) completeness, (2) positional accuracy, (3) thematic accuracy, (4) temporal accuracy, and (5) logical consistency (Guptill \& Morrison, 1995). In this study, two major aspects of internal data quality namely completeness and thematic accuracy are considered and their external use is discussed.

Following Figure 1, first, OSM features tagged with 'landuse' and 'natural' are retrieved and merged together into a unique dataset. Second, overlaps and topological errors in the dataset are then resolved to assure the logical consistency of features. Third, the OSM features are re-classified and matched according to the GMESUA nomenclature. Fourth, the percentage of completeness for each country/city is determined to measure how complete a certain city is mapped. Finally, an error matrix between the OSM and GMESUA datasets is computed to measure the overall thematic accuracy of the OSM features along with a detailed per-class analysis.

\section{Results and discussions}

\section{Completeness}

\section{Regional (European) scale}

Figure 2 represents the measured completeness indices across European countries. This is calculated based on the total mapped area in each country relate to total area of the corresponding country. The values are diverse. While only $1.6 \%$ of land use features in Iceland are mapped, $96 \%$ of Bosnia and Herzegovina are mapped.

More than half of Belgium, Bosnia \& Herzegovina, Germany, France, Luxemburg, the Netherlands, Romania, and Slovakia are mapped. Spatial distribution of the mapped features within Europe is displayed in Figure 3 by green cells. It should be noted that considering European countries with dissimilar population and physical patterns, these completeness values should not be used for judging the topology of citizen participations in OSM. For instance, Iceland with an area of $103,000 \mathrm{~km}^{2}$ and nearly 300,000 inhabitants is the least 


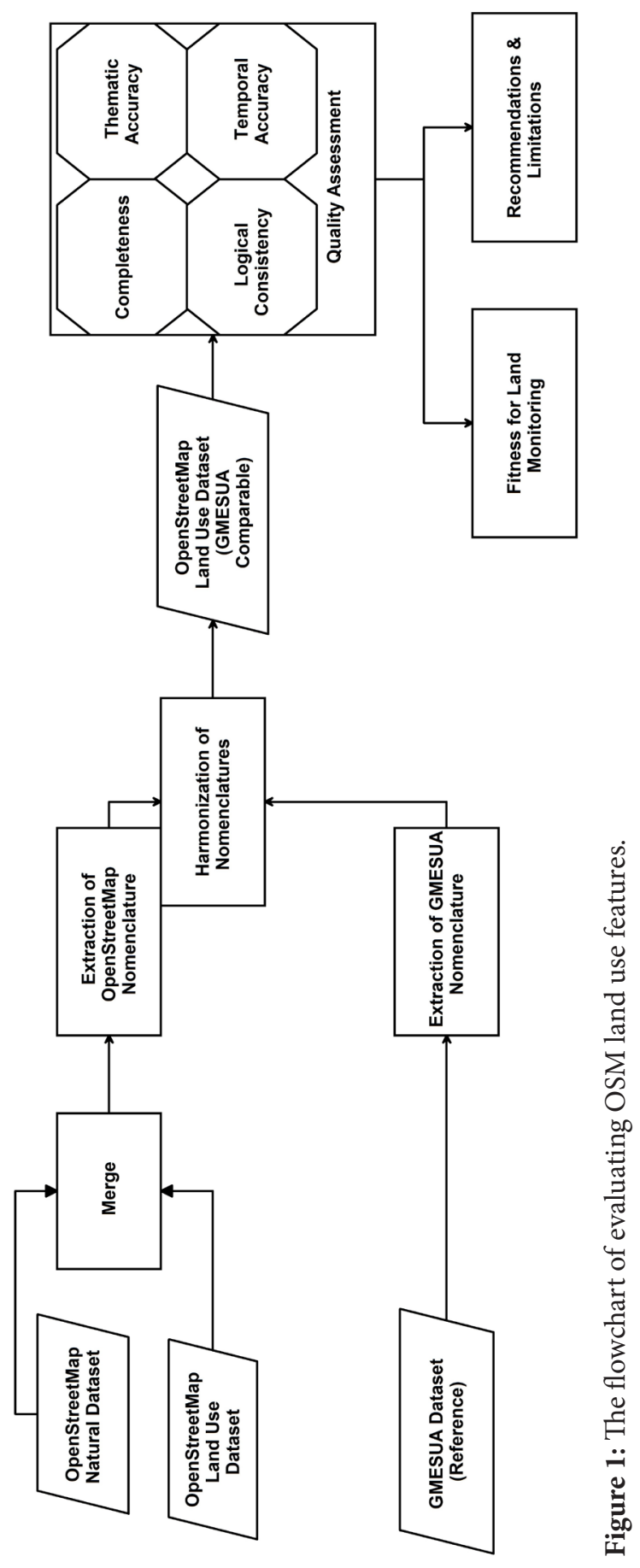




\section{Completeness (\%)}

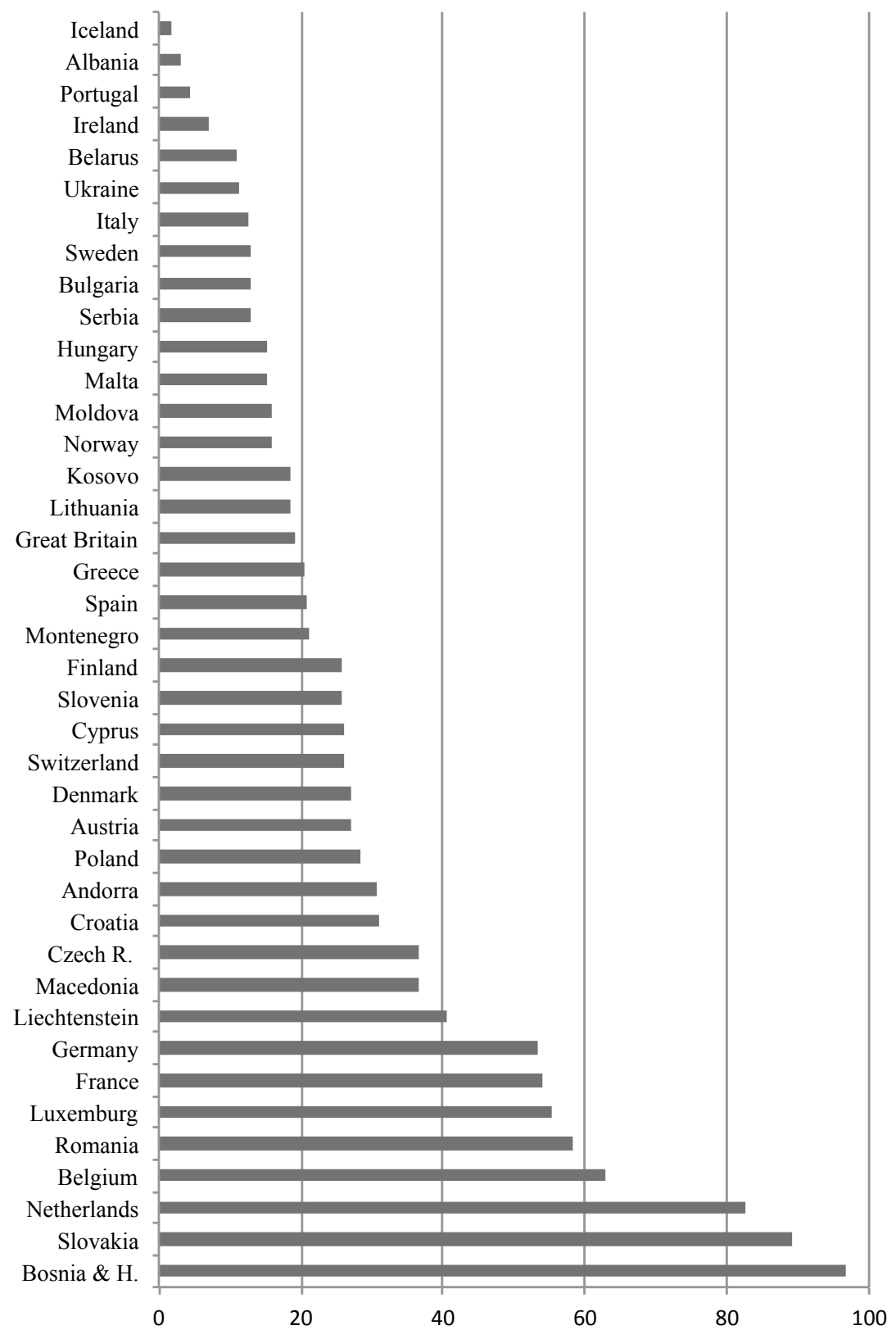

Figure 2: The calculated completeness index of OpenStreetMap land use features for European countries. 


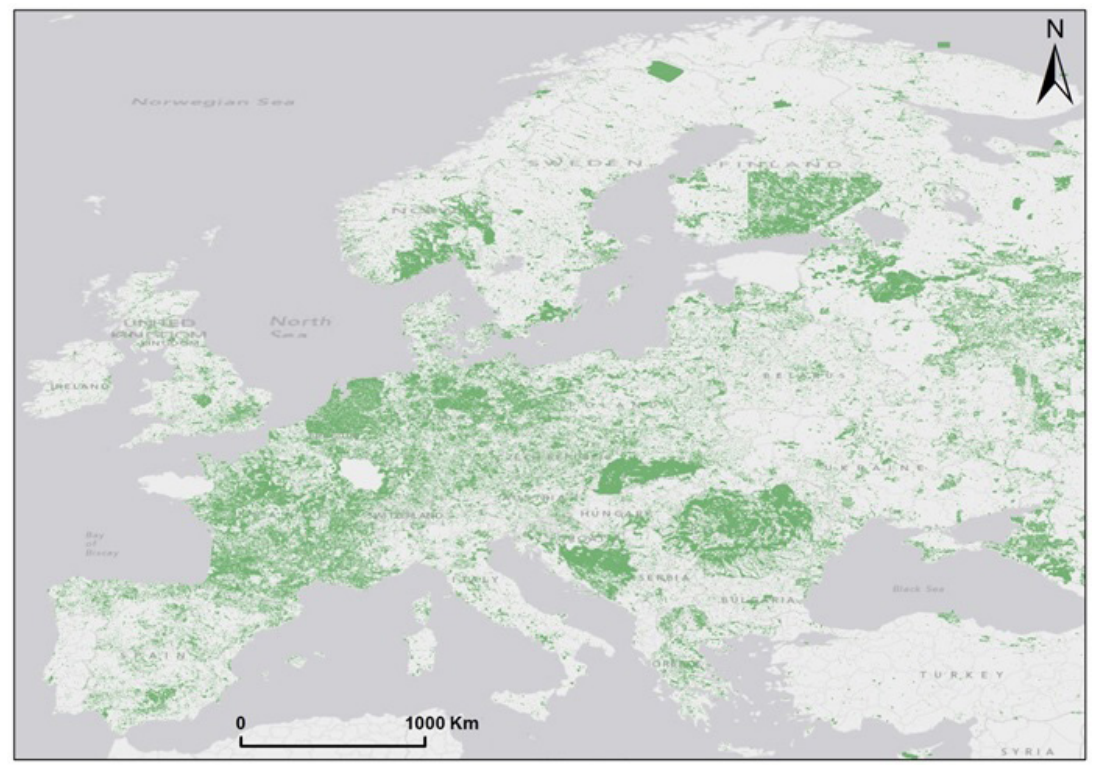

Figure 3: Spatial distribution of land use features from OpenStreetMap in Europe.

mapped country, which is not comparable with the Netherlands, holding an area of $41,500 \mathrm{~km}^{2}$ and nearly 17 million inhabitants, corresponding to one the best mapped countries (82\%). Likewise, while the completeness index for Sweden is reported as almost $13 \%$, almost more than half of this country is covered by forests. This justifies the low completeness index value as minor residents live there or mappers do not prioritize mapping forests. This heterogeneity and inequality of public participation should be further investigated as outlined in (Jokar Arsanjani \& Bakillah, 2015).

\section{Local (metropolitan) scale}

The degree of completeness at local level i.e. metropolitan area in several countries was checked and a wide range of values from 39\% for Frankfurt to 100\% for Bucharest was achieved. These values are shown in Figure 4.

\section{Thematic accuracy}

Apart from completeness, thematic accuracy is a key criterion to judge about the quality of the contributed LU features. This is meant to explore how properly the land parcels are tagged. Thematic accuracy is basically called 'accuracy 


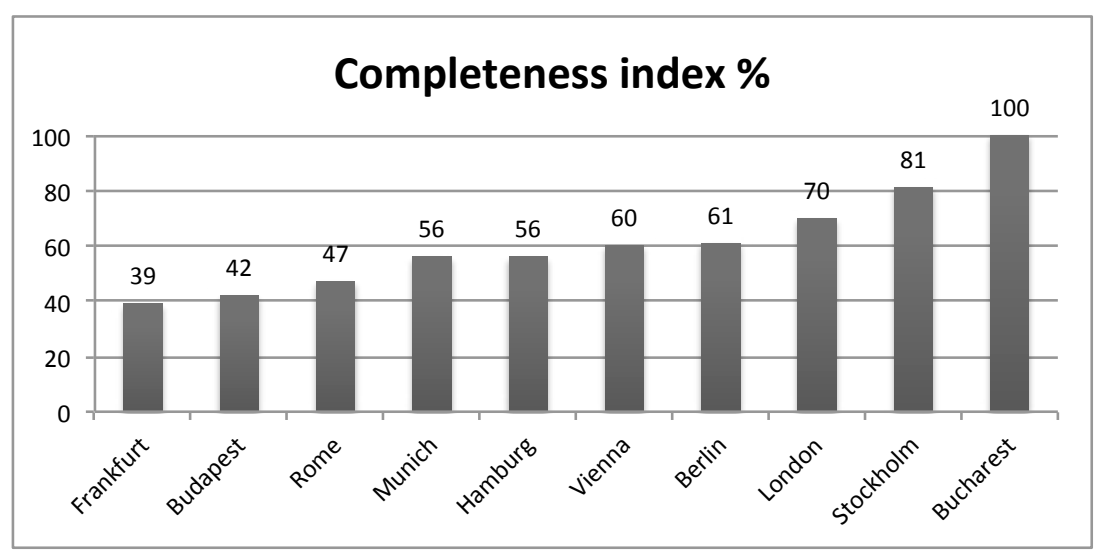

Figure 4: Completeness index of OpenStreetMap land use features for ten large metropolitan areas.

assessment' in the LU/LC classification studies, which reflects the difference between a target dataset against a reference dataset (Congalton, 1991; G. M. Foody et al., 2013; Giles M Foody, 2002). This is carried out through summarizing all data in a confusion matrix (i.e., error matrix) and calculating several indicators including 'overall/per class accuracies', 'Kappa index of agreement', 'user's accuracy' and 'producer's accuracy"' (Giles M Foody, 2002; Herold et al., 2008). In this study, a confusion matrix analysis is applied to reach these measures. A measure for the overall accuracy is calculated by dividing the number of identical pixels by the total number of pixels. However, it does not identify how well individual classes between the two datasets match. Hence, the user's accuracy and producer's accuracy should be calculated to measure the accuracy of each class (Herold et al. 2008). The user's accuracy indicates the probability that a pixel from the OSM LU map actually matches the GMESUA dataset, while the producer's accuracy refers to the probability that a specific LU type from the reference dataset is classified as such. These two measurements are not necessarily equal. For instance, if for a specific land type of 'farming', with accuracies achieved of $75 \%$ and $82 \%$ for user's accuracy and producer's accuracy respectively, it implies that as a user of the data, roughly $75 \%$ of all the pixels classified as 'farming' are the same in the reference dataset and, as a producer, only $82 \%$ of all 'farming' pixels are classified as such (Jokar Arsanjani et al., 2015).

In order to assess how well LU types in each city are mapped, Kappa index, overall accuracy, user's accuracy, and producer's accuracy, are calculated. Due to heterogeneous accuracies across cities, interpretation of the confusion matrix is discussed for each city separately in (Jokar Arsanjani, Mooney, Zipf, et al., 2015; Jokar Arsanjani \& Vaz, 2015). Further to this, the geographical distribution of agreements and disagreements is visualized in (Jokar Arsanjani, Mooney, Zipf, et al., 2015). In general, land classes such as Isolated structures [113], Industrial, 
commercial, public, military and private units [121], Road and rail networks and associated land [122], Sport and leisure facilities [142], Agricultural+seminatural+wetlands [200], Forests [300], and Water [500] show the highest level of agreement in the two datasets. In contrast, the remaining classes show disagreement, assuming that they are correctly reflected in the reference (GMESUA) dataset. This brings up the question whether OSM represents the right classification or the reference dataset. Finally, it can be concluded that the contributed OSM-LU features are heterogeneously distributed over inside/outside urban areas, which confirms the availability of LU features in both urban and rural areas.

\section{Conclusions and recommendations}

The recent emergence and rapid evolution of VGI platforms, such as OSM, has involved a massive number of citizens to collect and share geolocated information and attributes about geographical objects. This bottom-up process of collecting individuals' contributions has resulted in shaping big (geo)data, which has leveraged new applications such as indoor mapping (Goetz \& Zipf, 2010), routing applications (Bakillah et al., 2014), tourism recommendations (Sun, Fan, Bakillah, \& Zipf, 2013), and environmental monitoring (Fritz et al., 2012; Jokar Arsanjani \& Vaz, 2015). Although the question on how to attract users and how to keep them active in the crowdsourcing activities is yet to be addressed, OSM has shown its continuing success in attracting more than 2.7 million users. Thus, a considerable potential in OSM exists and is yet to be further explored. Thus, in this study, we comparatively evaluated the completeness aspect of the contributed OSM-LU features across Europe as well as their thematic accuracy in ten large metropolitan areas to find out how reliable we could start exploiting them.

Results show that from a thematic accuracy perspective, the thematic quality of OSM features range from 'moderate' to 'substantial' rank of Kappa indices and overall accuracies. Per-class analysis of the LU types shows that, depending on the city, Isolated structures [113], Industrial, commercial, public, military and private units [121], Road and rail networks and associated land [122], Sport and leisure facilities [142], Agricultural+semi-natural+wetlands [200], Forests [300] and Water [500] reach the 'substantial' rank of accuracies, which means that these classes are highly useable. It should be noted that integrating ground-truth information with other reference data for accuracy assessment could be an alternative approach for producing hybrid LU datasets.

From a temporal accuracy perspective, archived images from within 20052010 have been used for LU mapping and this could have caused the abovementioned disagreements, whereas the OSM-LU features have mainly been uploaded within since 2009, and therefore, some information from OSM might be even more close to reality than our reference data. Moreover, the MMU of 
the GMESUA datasets is $0.25-1$ ha and, therefore, land parcels smaller than this MMU are ignored in the course of mapping, while in OSM even smaller parcels are mapped, i.e. a smaller MMU in OSM is possible. This means that in some parts while a polygon in GMESUA dataset is representing a specific LU type, the same area in OSM-LU dataset is covered by multiple small polygons showing multiple land types.

Concerning the volunteers' recognition of LU features, the citizens' perception of LU types should be further investigated to understand the way they visually interpret $\mathrm{LU}$ types from the online image libraries in OSM. As a final conclusion, the OSM-LU features message a promising data source for updating LU inventories. Certainly, the longer OSM exists, the more contributions will be received and consequently higher data quality can be achieved.

This study points out some other recommendations to the LU researchers, environmental scientists, policy makers, among others that will lead future research possibly in more suitable directions. Based on the presented completeness indices across Europe, as well as the accuracy values of the selected cities, the contributed OSM-LU features account for a potential alternative data source for mapping LU. Further studies on other areas must be conducted to explore the heterogeneity of completeness and thematic accuracy across space. Furthermore, applying data mining techniques and data fusion with national and regional datasets (e.g., GMESUA) for extracting the LU information of unmapped areas are of high importance. Additionally, the land types with the highest reliability can be separately incorporated into respective applications. This enables experts to: (a) possibly find ways to draw the attention of volunteer mappers to mapping LU features by highlighting their importance for more effective environmental monitoring, (b) possibly improve the OSM ontology of the LU dataset, (c) maximize the efficiency of OSM for LU mapping as users are not able to add further features in the urban areas, because the massive volume of mapped objects (e.g. POIs, roads, building, etc.) do not let users to have enough space for adding LU features.

\section{Acknowledgments}

The authors would like to acknowledge the support and contribution of COST Actions TD1202 "Mapping and Citizen Sensor" http://www.citizen-sensorcost.eu and IC1203 "ENERGIC" http://vgibox.eu/.

\section{References}

Arino, O., Ramos Perez, J. J., Kalogirou, V., Bontemps, S., Defourny, P., \& Van Bogaert, E. 2012. Global Land Cover Map for 2009 (GlobCover 2009). PANGAEA. DOI: http://dx.doi.org/10.1594/PANGAEA.787668 
Bakillah, M., Lauer, J., Liang, S. H. L., Zipf, A., Jokar Arsanjani, J., Mobasheri, A., \& Loos, L. 2014. Exploiting Big VGI to Improve Routing and Navigation Services. In Big Data Techniques and Technologies in Geoinformatics. CRC Press, pp. 177-192.

Büttner, G., Feranec, J., \& Gabriel, J. 2002. Corine land cover update 2000. Retrieved from: http://www.fomento.es/nr/rdonlyres/de88aec2-d5fa-4e959694-939a326cd026/3128/021219techrep89.pdf.

Cihlar, J., \& Jansen, L. J. M. 2001. From Land Cover to Land Use: A Methodology for Efficient Land Use Mapping over Large Areas. The Professional Geographer, 53(2): 275-289. DOI: http://dx.doi.org/10.1111/0033-0124. 00285

Congalton, R. G. 1991. A review of assessing the accuracy of classifications of remotely sensed data. Remote Sensing of Environment, 37(1): 35-46. DOI: http://dx.doi.org/10.1016/0034-4257(91)90048-B

De Leeuw, J., Said, M., Ortegah, L., Nagda, S., Georgiadou, Y., \& DeBlois, M. 2011. An Assessment of the Accuracy of Volunteered Road Map Production in Western Kenya. Remote Sensing, 3(12): 247-256. DOI: http://dx.doi. org/10.3390/rs3020247

De Sherbinin, A. 2002. A CIESIN thematic guide to land land-use and land land-cover change (LUCC). NY, USA. Retrieved from: http://sedac.ciesin. columbia.edu/binaries/web/sedac/thematic-guides/ciesin_lucc_tg.pdf.

Devillers, R., Bédard, Y., Jeansoulin, R., \& Moulin, B. 2007. Towards spatial data quality information analysis tools for experts assessing the fitness for use of spatial data. Int. J. Geogr. Inf. Sci., 21(3): 261-282. DOI: http://dx.doi. org/10.1080/13658810600911879

Ellis, E. 2007. Land-use and land-cover change. In Earth. Retrieved from: http://www.eoearth.org/article/Land-use_and_land-cover_change.

European Union. 2011. Mapping Guide for a European Urban Atlas. Retrieved from: http://www.eea.europa.eu/data-and-maps/data/urban-atlas/mapping-guide/ urban_atlas_2006_mapping_guide_v2_final.pdf/download

Flanagin, A. J., \& Metzger, M. J. 2008. The credibility of volunteered geographic information. GeoJournal, 72(3-4): 137-148. DOI: http://dx.doi. org/10.1007/s10708-008-9188-y

Fonte, C. C., Bastin, L., See, L., Foody, G., \& Lupia, F. 2015. Usability of VGI for validation of land cover maps. International Journal of Geographical Information Science, 29(7): 1269-1291. DOI: http://dx.doi.org/10.1080/1365881 6.2015 .1018266

Foody, G. M. 2002. Status of land cover classification accuracy assessment, 80: $185-201$.

Foody, G. M., See, L., Fritz, S., Van der Velde, M., Perger, C., Schill, C., \& Boyd, D. S. 2013. Assessing the Accuracy of Volunteered Geographic Information arising from Multiple Contributors to an Internet Based Collaborative Project. Transactions in GIS, (828332): n/a-n/a. DOI: http://dx.doi. org/10.1111/tgis.12033 
Fritz, S., Bartholomé, E., Belward, A., Hartley, A., Stibig, H. J., Eva, H., ..., others. 2003. Harmonisation, mosaicing and production of the Global Land Cover 2000 database (Beta Version). Office for Official Publications of the European Communities Luxembourg.

Fritz, S., Mccallum, I., Schill, C., Perger, C., See, L., Schepaschenko, D., ..., Velde, M. Van Der. 2012. Geo-Wiki: An online platform for improving global land cover. Environmental Modelling \& Software, 31(0): 110-123. DOI: http://dx.doi.org/10.1016/j.envsoft.2011.11.015

Gervais, M., Bédard, Y., Levesque, M., Bernier, E., \& Devillers, R. 2009. Data quality issues and geographic knowledge discovery. Geographic Data Mining and Knowledge Discovery: 99-115.

Goetz, M., \& Zipf, A. 2010. Extending OpenStreetMap to Indoor Environments : Bringing Volunteered Geographic Information to the Next Level, (Hansen 2004).

Guptill, S. C., \& Morrison, J. L. 1995. Elements of spatial data quality. Oxford [etc.]: Elsevier Science.

Herold, M., Mayaux, P., Woodcock, C. E., Baccini, A., \& Schmullius, C. 2008. Some challenges in global land cover mapping: An assessment of agreement and accuracy in existing $1 \mathrm{~km}$ datasets, 112: 2538-2556. DOI: http:// dx.doi.org/10.1016/j.rse.2007.11.013

Jokar Arsanjani, J., \& Bakillah, M. 2015. Understanding the potential relationship between the socio-economic variables and contributions to OpenStreetMap. International Journal of Digital Earth, 0(0): 1-16. DOI: http:// dx.doi.org/10.1080/17538947.2014.951081

Jokar Arsanjani, J., Barron, C., Bakillah, M., Helbich, M., \& Arsanjani, J. J. 2013. Assessing the Quality of OpenStreetMap Contributors together with their Contributions. In 16th AGILE International Conference on Geographic Information Science. Leuven, Belgium, pp. 14-17. Retrieved from: http:// www.agile-online.org/Conference_Paper/CDs/agile_2013/Short_Papers/ SP_S4.2_Arsanjani.pdf.

Jokar Arsanjani, J., Helbich, M., Bakillah, M., Hagenauer, J., \& Zipf, A. 2013. Toward mapping land-use patterns from volunteered geographic information. International Journal of Geographical Information Science, 27(12): 2264-2278. DOI: http://dx.doi.org/10.1080/13658816.2013.800871

Jokar Arsanjani, J., Helbich, M., Bakillah, M., \& Loos, L. 2015. The emergence and evolution of OpenStreetMap: a cellular automata approach. International Journal of Digital Earth, 8(1): 76-90. DOI: http://dx.doi.org/10.1080 /17538947.2013.847125

Jokar Arsanjani, J., Mooney, P., Helbich, M., \& Zipf, A. 2015. An exploration of future patterns of the contributions to OpenStreetMap and development of a Contribution Index. Transactions in GIS, 19(6): 869-914. DOI: http:// dx.doi.org/10.1111/tgis.12139

Jokar Arsanjani, J., Mooney, P., Zipf, A., \& Schauss, A. 2015. Quality assessment of the contributed land use information from OpenStreetMap versus 
authoritative datasets. In: Jokar Arsanjani, J., Zipf, A., Mooney, P., \& Helbich, M., (Eds.) OpenStreetMap in GIScience: experiences, research, applications. Springer.

Jokar Arsanjani, J., \& Vaz, E. 2015. An assessment of a collaborative mapping approach for exploring land use patterns for several European metropolises. International Journal of Applied Earth Observation and Geoinformation, 35(0): 329-337. DOI: http://dx.doi.org/10.1016/j.jag.2014.09.009

Kong, F., Yin, H., Nakagoshi, N., \& James, P. 2012. Simulating urban growth processes incorporating a potential model with spatial metrics. Ecological Indicators, 20: 82-91. DOI: http://dx.doi.org/10.1016/j.ecolind.2012.02.003

Koukoletsos, T., Haklay, M., \& Ellul, C. 2012. Assessing Data Completeness of VGI through an Automated Matching Procedure for Linear Data. Transactions in GIS, (Goodchild 2007), no-no. DOI: http://dx.doi.org/10.1111/ j.1467-9671.2012.01304.x

Ludwig, I., Voss, A., \& Krause-Traudes, M. 2011. A Comparison of the Street Networks of Navteq and OSM in Germany. In: Geertman, S., Reinhardt, W., \& Toppen, F. (Eds.) Advancing Geoinformation Science for a Changing World SE - 4. Springer Berlin Heidelberg, pp. 65-84. DOI: http://dx.doi. org/10.1007/978-3-642-19789-5_4

McIver, D., \& Friedl, M. 2002. Using prior probabilities in decision-tree classification of remotely sensed data. Remote Sensing of Environment, 81(2-3): 253-261. DOI: http://dx.doi.org/10.1016/S0034-4257(02)00003-2

Mooney, P., \& Corcoran, P. 2012. OpenStreetMap, 16(4): 561-579. DOI: http:// dx.doi.org/10.1111/j.1467-9671.2012.01306.x

Qi, Z., Yeh, A. G.-O., Li, X., \& Lin, Z. 2012. A novel algorithm for land use and land cover classification using RADARSAT-2 polarimetric SAR data. Remote Sensing of Environment, 118(0): 21-39. Retrieved from: http://www. sciencedirect.com/science/article/pii/S0034425711003877.

Ramm, F. 2014. OpenStreetMap Data in Layered GIS Format. Retrieved from: http://www.geofabrik.de/data/geofabrik-osm-gis-standard-0.6.pdf.

Ramm, F., Names, I., Files, S. S., Catalogue, F., Features, P., Features, N., ..., Cars, C. 2011. OpenStreetMap Data in Layered GIS Format, pp. 1-21.

Rouse, L. J., Bergeron, S. J., \& Harris, T. M. 2007. Participating in the Geospatial Web: Collaborative Mapping, Social Networks and Participatory GIS. In: Scharl, A., \& Tochtermann, K., (Eds.), The Geospatial Web. Springer London, pp. 153-158. Retrieved from: http://dx.doi.org/10.1007/978-1-84628-827-2_14 Saadat, H., Adamowski, J., Bonnell, R., Sharifi, F., Namdar, M., \& Ale-Ebrahim, S. 2011. Land use and land cover classification over a large area in Iran based on single date analysis of satellite imagery. ISPRS Journal of Photogrammetry and Remote Sensing, 66(5): 608-619. Retrieved from: http:// www.sciencedirect.com/science/article/pii/S0924271611000517.

Seifert, F. 2009. Improving Urban Monitoring toward a European Urban Atlas. In: Global Mapping of Human Settlement. CRC Press. DOI: http://dx.doi. org/10.1201/9781420083408-c11 
Sun, Y., Fan, H., Bakillah, M., \& Zipf, A. 2013. Road-based travel recommendation using geo-tagged images. Computers, Environment and Urban Systems. DOI: http://dx.doi.org/10.1016/j.compenvurbsys.2013.07.006

van Oort, P. 2006. Spatial data quality: From Description to Application. Wageningen University.

Vaz, E., Walczynska, A., \& Nijkamp, P. 2013. Regional challenges in tourist wetland systems: an integrated approach to the Ria Formosa in the Algarve, Portugal. Regional Environmental Change, 13(1): 33-42. DOI: http://dx.doi. org/10.1007/s10113-012-0310-9

Wästfelt, A., \& Arnberg, W. 2013. Local spatial context measurements used to explore the relationship between land cover and land use functions. International Journal of Applied Earth Observation and Geoinformation, 23(0): 234-244. DOI: http://dx.doi.org/10.1016/j.jag.2012.09.006 